\title{
Quantitative or Semi-Quantitative PCR: Reality Versus Myth
}

\author{
Francois Ferre
}

The Immune Response Corporation, Carlsbad, California 92008

\begin{abstract}
A Ithough PCR is beginning to come of age, it is still quite common to read in the literature such statements as "PCR is not really a quantitative method" or "PCR has been shown at best to be a semi-quantitative procedure." Why is that in 1992 many people are still reluctant to associate PCR and quantitation of nucleic acids? I believe this misconception is the unfortunate result of a constant questioning of the credibility of PCR as being incapable of quantitative analysis.

Initially, PCR was not viewed as having great quantitative power, an opinion exemplified by the fact that the first two books on PCR technology had no mention of quantitation. ${ }^{(1,2)}$ Indeed, it should come as no surprise that the factor that makes PCR so powerful, i.e., its ability to amplify small amounts of nucleic acids, exponentially ${ }^{(3,4)}$ is also the factor that makes the technique so challenging as a quantitative method. Anything that is capable of interfering with the exponential amplification might ruin the intrinsic quantitative ability of PCR. ${ }^{(5)}$ Therefore, the art of quantitative PCR is devoted to minimizing the amount of interference with the actual doubling of the target amplicon at each cycle and compensating for the inescapable, even if minimized, interference with the very doubling.
\end{abstract}

\section{PCR: A TOOL FOR QUANTITATION OF NUCLEIC ACIDS}

Currently, there is no doubt that PCR can be made quantitative. In a number of publications, the quantitative capability of PCR has been demonstrated by comparing it to classical means of nucleic acids quantitation, such as North- ern blot or slot blot analyses. Noonan et al. ${ }^{(6)}$ have reported that the results of PCR-based quantitation of multidrug resistance (MDR1) gene expression in MDRKB cell lines show a good correlation with results obtained by the traditional slot blot technology. ${ }^{(6)}$ The proportionality in the relative amount of MDR1 RNA from a number of different cell lines was equivalent with both methods. Similar results were obtained when comparing MDR1 gene expression by quantitative PCR and Northern blot methodology. ${ }^{(7)}$ Quantitative PCR has also been shown to correlate with in situ hybridization. This was nicely exemplified by Park and Mayo, who studied the temporal expression and localization of the progesterone receptor $(\mathrm{PR}) \mathrm{mRNA}$ in the rat ovary. Their results demonstrated that an equivalent proportionality in the relative amount of RNA was obtained by both PCR and in situ hybridization. ${ }^{(8)}$ All the above examples refer to relative quantitation by PCR, i.e., a relative difference in the amount of targets was quantitated rather than the real number of nucleic acid copies. One of the landmark papers on quantitative PCR was published in 1989 by Alice Wang and colleagues. ${ }^{(9)}$ They not only reported relative quantitation, but they also claimed that they were able to achieve absolute quantitation. In other words, the amount of IL-1 $\alpha$ mRNA they measured, $1.1 \times 10^{4}$ in $1 \mathrm{ng}$ of LPS-induced macrophage total RNA, was accurate. Proof of this was demonstrated by the fact that their quantitative PCR data correlated extremely well with data obtained with the Northern blot analysis.

To substantiate further the quantitative nature of PCR, I would like to review the factors affecting the quantitative power of PCR, such as the level of optimization of the amplification step and the standards utilized, as well as the methods of detection and quantitation of the amplicons. I will then discuss how to enhance the quantitative credibility of PCR procedures.

\section{FACTORS AFFECTING THE QUANTITATIVE POWER OF PCR}

Although oversimplified, quantitative power can be defined as being the level of reproducibility, precision, and accuracy achievable when quantitating a specified amount of nucleic acids. The key factors that influence the quantitative ability of a PCR procedure are the following:

1. Optimization of the amplification step. As already mentioned, the optimization of the amplification process is a major factor in quantitations. Optimization might involve changes in nucleic acids preparation, in primer usage, in buffer usage and in cycling parameters. Most of these parameters have been reviewed previously. ${ }^{(1,2,10-13)}$

2. Hot start and new tricks. One of the recent developments in PCR optimization is to recognize the importance of eliminating some undesired hybridization events that often happen in the first cycle and can carry potentially devastating effects. Mullis et al. ${ }^{(5,14)}$ have shown that by starting the reaction at high temperature-hot-start PCR-instead of at room temperature, the sensitivity of PCR can be improved by a 1000 -fold when starting from very few target molecules in the presence of $1 \mu \mathrm{g}$ of genomic DNA.

Another method can be employed at the level of DNA preparation; it consists of boiling the cell lysate up to $2 \mathrm{hr}$, in- 
stead of the common 5-10 min prior to amplification. ${ }^{(15,16)}$ A 10 -fold increase in sensitivity has been achieved this way, particularly when one is using large amounts of starting genomic DNA. ${ }^{(16)}$ Because the boiling process cleaves the DNA molecules, it is plausible that the enhancement in sensitivity might be due to a reduction in the overall background generated. Indeed, very few molecules besides the target would now possess enough sequence homology for both primers to land efficiently during the first and subsequent cycles. Therefore, the boiling process could mimic the hot start procedure in that it might greatly reduce the chances of amplifying non-target molecules from the very first cycle. Needless to say this procedure, contrary to the hot start, is not necessarily applicable to all systems, and might not even be appropriate for the amplification of large fragments (>1000 bp).

Finally, if hot start or the boiling process still do not provide the level of specificity needed to enhance sensitivity to the required level, one can experiment with enhancers such as the Perfect Match Polymerase Enhancer from Stratagene. ${ }^{(17)}$ This product, whose composition is proprietary, appears to increase greatly the yield and specificity of polymerase-catalyzed primer extension reactions. However, this effect is dependent upon the specific primer/template combination.

The above methods not only can produce an increase in sensitivity, but, more importantly, they can also enhance quite dramatically the reproducibility of the amplification and thus of the quantitation.

3. Linear range of amplification. The amplification process can be described with the following basic equation: $Y_{n}=(1+R) n$ where $Y_{n}$ is the amplification factor after $n$ cycles and $R$ is the efficiency of amplification at each cycle. Therefore, theoretically, if the amplification precedes with an efficiency of $100 \%$ $(R=1)$, the amount of amplicons is doubling at each cycle. However, in most PCR procedures, the overall efficiency is less than $100 \%$ and a typical amplification runs with a constant efficiency of about $70-80 \%$ from the 15 th cycle to the 30th cycle, depending on the amount of starting material. ${ }^{(9,43)}$ Indeed, the increase in the amount of amplicons stays exponential only for a limited number of cycles, after which the ampli- fication rate reaches a plateau. The factors that contribute to this plateau phenomenon include substrate saturation of enzyme, product strand reannealing, and incomplete product strand separation. In this latter phase, the quantitated amount of amplified product is no longer proportional to the starting amount of target molecules. Therefore, to make PCR suitable in quantitative settings, it is imperative that a balance be found between a constant efficiency and an exponential phase in the amplification process. This will ultimately depend on the number of cycles, on the amount of targets in the starting material, and on the system of detection and quantitation of the amplified product. The ultimate goal of these considerations is to identify the linear range of the reaction in which the quantitated amount of amplified target is proportional to the initial amount of target molecules. Thus, linear range (or range of proportionality) might be defined as being the assays' window in which quantitation is amenable.

Kellog et al. ${ }^{(18)}$ have shown that the linear range of amplification was from 3200 to 51,200 copies of HIV-1 plasmid DNA in the presence of $1 \mu \mathrm{g}$ of human placental DNA with 20 cycles, from 200 to 3200 copies with 25 cycles, and from 12 to 400 copies with 30 cycles. This range was achieved using a slot-blot format with a ${ }^{32}$ P-labeled oligonucleotide probe. Two other groups have also determined that the amplification of 10-1000 copies of HIV with 30 cycles falls into the linear range of the reaction. ${ }^{(15,19)}$ Either a liquid hybridization with radioactive probes or a direct labeling of the amplicons with ${ }^{32} \mathrm{P}$ end-labeled primers was used for detection of the products. All three groups used a radioanalytic imaging system (from AMBIS) for quantitation.

These examples were chosen because they illustrate quantitative procedures that were pushed close to the limits of nucleic acid quantitation. Indeed, I would argue that it is quite difficult to find more challenging conditions for performing quantitative PCR. First, it is clear that 10 copies of a given target diluted in $1 \mu \mathrm{g}$ of background DNA represent an infinitesimal amount of specific DNA sequences drowning in an ocean of DNA bases. Second, quantitation below 10 copies is very difficult and cumbersome to achieve because it requires numerous runs per sample to integrate the stochastic partition of the target molecules in the quantitative analysis.

From the above three examples, one can also conclude that by using three different experimental conditions (different labeling modalities, HIV standards, and researchers), a similar linear range of amplification was obtained with the same type of substrate. It should follow that one should be able to conduct quantitative analyses with either of the three procedures and get very similar answers. Unfortunately, other parameters must be also considered. For example, the level of reproducibility and precision attached to such quantitative analyses will be dependent on the level of precision in the assessment of the amount of total genomic DNA that can be used to normalize the HIV-1 DNA copy number. I will come back to this very important issue in a few paragraphs.

Proportionality in the yield of PCR products over 2-3 logs can also be achieved with a defined number of cycles using RNA as starting material (RTPCR). Holodniy et al. ${ }^{(20,21)}$ have reported that by applying RT-PCR with 30 cycles for the quantitation of HIV-1 RNA in plasma, the linear range encompasses 2 logs, from $10^{2}$ to $10^{4} \mathrm{TCID}_{50}$ of $\mathrm{HIV}_{\text {IIIB }}$ virus stock. Similarly, we have also demonstrated that for the quantitation of gag HIV-1 mRNA, proportionality was preserved between 100 and 10,000 target molecules. These values were calculated from a known number of synthetic RNA coamplified with the HIV target. $^{(22)} \mathrm{Fi}$ nally, Noonan et al., ${ }^{(6)}$ quantitating the amount of MDR1 mRNA in MDR KB cell lines, have shown that with 20 cycles the relative yield of PCR products is linear over the range of 1-100 copies of MDR1 cDNA per cell. Very different methods for the detection and subsequent quantitation of the amplicons, including nonisotopic enzyme-linked affinity assay, ${ }^{32} \mathrm{P}$ end-labeled primer, and $\left[\alpha-{ }^{32} \mathrm{P}\right] \mathrm{dCTP}$ labeling of the extended primer, were used in the three above examples, respectively. To summarize, it appears that when using either RNA or DNA as starting material, linear ranges of amplification can be defined and readily obtained.

\section{STANDARDS FOR QUANTITATION}

In most quantitative PCR procedures, the linear range of the amplification was evaluated on control samples or stan- 
dards. To be suitable in defining the window of proportionality, the standard samples should be very close in composition to what is being tested. This is usually easily achievable for DNA controls.

\section{DNA Standards}

In almost all quantitative DNA PCR procedures, the standards are amplified in separate PCR vessels and the data are utilized to create standard curves. For example, if the goal is to monitor the viral DNA load in HIV-infected individuals undergoing therapy, a good standard could be obtained by dilution of HIV DNA in seronegative peripheral blood mononuclear cells (PBMCs). ${ }^{(15,16,18,19,23-27)}$ One of the best sources of HIV DNA is a cell line carrying a known amount of integrated HIV genomes, and preferentially one would even choose a cell line with only one genome per cell. ${ }^{(15,19,23,27)}$ Such controls could be ultimately used for absolute quantitation.

Quantitative analysis of specific nucleic acids implies also that the amount of starting material must be estimated either by cell counting ${ }^{(15)}$ or by O.D. reading at $260 / 280$ if the starting material consists of purified nucleic acid. ${ }^{(25,28,29)}$ PCR can also be used to quantitate retrospectively the amount of starting material and offers the advantage of working on a cell lysate for the quantitation of DNA targets. In the above HIV example, quantitation could be improved by normalizing the HIV DNA load to the human genomic DNA load in the sample. Numerous standards for quantitation of the genomic DNA content have been utilized, the most commonly used being $\beta$-globin and HLA genes. ${ }^{(15,18,23,24)}$ A coamplification of the specific DNA sequence under investigation and a genomic DNA target in the analyzed samples can then be performed. This should add to the quantitative power of the assay because any fluctuation in the amplification efficiency should be reflected on both amplicons. Thus, a loss of efficiency in the amplification of the studied amplicon can be compensated for through the normalization process using the coamplified genomic DNA target. ${ }^{(15)}$ The obvious prerequisite is that both amplifications do not interfere with each other. However, slight differences in efficiency of amplification between both sets of primers is tolerated because quantitation will be obtained after extrapolation from the two standard curves.

This is not the case in assay formats in which coamplified controls are directly used for quantitation. The internal controls are often modified versions of the targets and contain the same primer sequences to insure equivalent efficiency in the amplification process. ${ }^{(30)}$ This last PCR assay format is the exception for DNA but is commonly used for the quantitative analysis of RNA targets.

\section{RNA Standards}

The search for adequate standards for RNA quantitation is much more challenging. Some investigators have used external or internal DNA standards ${ }^{(31-35)}$ for the quantitation of RNA targets, but in those instances any fluctuations in the efficiency of the reverse-transcription (RT) step are not taken into account. Controlling only one of the enzymatic reactions represents a handicap for quantitation. Indeed, the efficiency for the cDNA synthesis step is variable between methods, and ranges from $5 \%$ to $90 \%{ }^{(6,34,36)}$ To address this issue, a number of investigators have employed an external RNA control. ${ }^{(7,20,37,38)}$ However, some variability has also been reported within the same assay, with up to $200-300 \%$ difference in duplicated reactions. ${ }^{(22,39)}$ Thus, it follows that internal RNA standards should be better suited for RNA quantitation.

A number of groups have developed procedures for the quantitative estimation of low-abundance mRNAs in which the systems are calibrated by coamplifying a relatively invariant $\operatorname{mRNA}^{(6,40,41,58)}$ or a known amount of an unrelated template $\mathrm{RNA}^{(42,43)}$ together with the investigated mRNA. As already mentioned, there are two prerequisites for such relative quantitations: The first one stipulates that the quantitation should be done in the exponential phase of the amplification process, and the second specifies that both amplicons should be amplified with the same efficiency. A third condition can be added at this point by stipulating that the control sequence should be present at an abundance comparable to that of the target sequence, thereby having similar amplification kinetics. ${ }^{(6,36)}$ This last requirement represents an obvious limitation for this quantitative RNA PCR format.
One could argue that the ultimate standard for RNA quantitation is one that is similar to the RNA control proposed by Wang et al. ${ }^{(9)}$ It consists of a synthetic internal standard that uses the same primer sequences as the target mRNA but yields a PCR product of different size. Thus, a methodology based on such a standard should address all three prerequisites for RNA quantitation described above. This type of control is now widely employed ${ }^{(22,44,45)}$ and it possesses the merit of being ultimately capable of absolute quantitation when using the proper conditions. However, contrary to the endogenous mRNA control approach, this procedure does not take into account the extent of possible degradation of the tested RNA preparation and relies on the quantitation of the starting material by O.D. readings. Furthermore, because both RNAs have different sizes and different nucleotide sequences between the two primers, changes in the secondary structure of the mRNA may occur. This, in turn, could lead to a difference in processivity of the reverse transcriptase and thus could bias quantitation when absolute evaluation of the RNA content is at stake. ${ }^{(45)}$ To exclude the influence of fragment size on the efficiency of PCR, control cDNA can be generated from wild-type template by mutation of a restriction site..$^{(31,46-48)}$ The ratio of coamplified target RNA to standard RNA can then be determined after restriction endonuclease digestion and separation by gel electrophoresis. However, in this case heteroduplex formation will affect the reliable calculation of transcript concentration by up to a factor of $3 .^{(31,46)}$

\section{METHODS OF DETECTION AND QUANTITATION}

The following section surveys current trends for methods of detection and quantitation. ${ }^{32}$ P-Labeled nucleotides still represent the most commonly used tags for the detection and quantitation of amplicons. More investigators $^{(6,9,24,31)}$ are now using direct labeling of the amplicons instead of the old format of probe detection. There are a number of reasons for this shift: (1) because quantitation requires a great deal of optimization at the amplification level, the extra specificity brought by probing is usually not necessary; (2) the direct-labeling is faster and easier to run; 
and (3) the procedure potentially has a greater quantitative power because it allows a more direct reading of the amplicon's accumulation. The amplified product can be tagged either with a ${ }^{32} \mathrm{P}$. end-labeled primer or with a $\left[\alpha^{32} \mathrm{P}\right]$ dXTP during the extension phase.

Procedures using end-labeling of the primer offer a higher sensitivity over procedures using the $\alpha$-labeling because the percentage of labeled amplicons generated is much greater (up to a log higher). Indeed, one cannot simply lower the concentration of the corresponding nonradioactive $\mathrm{dXTP}$ in the dNTP stock to increase specific activity because it may interfere substantially with the amplification. ${ }^{(31)}$ As an example, my colleagues and I have found that the end-labeling approach is well suited for the quantitation of $10 \mathrm{HIV}-1$ targets in a background of $4 \times 10^{5}$ PBMCs. ${ }^{(15)}$ More investigators are also turning to radioimaging and direct quantitation systems, ${ }^{(15,16,23,49)}$ such as the AMBIS system, instead of cutting bands from gels and counting cpm in vials. Radioimaging offers precise quantitation with a dynamic range of 5 orders of magnitude whereas autoradiography's linear response range is limited to less than 3 orders of magnitude. Thus, radioimaging should be superior to densitometry scanning for quantitation. By combining direct labeling of the amplicons and radioimaging of the gels, quantitative results can be obtained rather rapidly in less than a day. The major drawback in using ${ }^{32} \mathrm{P}$ labeling is linked to safety issues. We have tried ${ }^{35} \mathrm{~S}$ end-labeling as an alternative to ${ }^{32} \mathrm{P}$, but the level of sensitivity was far too low to get the $30 \mathrm{HIV}$ copies from the above example. Currently we are investigating the ${ }^{33} \mathrm{P}$, isomer which might represent a safe and sensitive alternative to ${ }^{32} \mathrm{P}$.

However, more researchers are directing their efforts toward replacing radioactive detection with equally sensitive nonradioactive techniques. As previously mentioned, a wider linear range is obtained by counting particles ( 5 logs for radioimaging) than by measuring transmittance of light (less than 3 logs for the scanning of an autoradiogram). Because this rule obviously also applies to nonradioactive systems, it follows that the most promising approaches are also linked to the counting of particles. This can be achieved by chemiluminescence in a format where the emission of photons is effectively counted. ${ }^{(27,50)} \mathrm{Ar}$ nold et al. ${ }^{(50)}$ have developed a method of labeling that results in attachment of a highly sensitive, nonradioactive acridinium ester (AE) reporter group to oligonucleotides. ${ }^{(50)}$ These highly chemiluminescent probes are sensitive to alkaline hydrolysis when they remain single stranded, but are considerably more resistant to hydrolysis when hybridized to the target DNA. Once hydrolyzed, the $\mathrm{AE}$ groups are no longer chemiluminescent. This method of hybridization, selective degradation, and detection, which requires no physical separation, is referred to as the hybridization protection assay and has been applied to the quantitation of HIV-1 DNA. ${ }^{(27)}$ The use of the Southern blotting format to quantitate DNA with chemiluminesent probes and photoanalytic imaging systems is also currently under intense investigations. Fluorescent tags can also be potentially adequate for quantitative studies. ${ }^{(28,63)}$ More data will be needed to address fully the value of these technologies in quantitative settings.

A number of quantitative methods have been developed around nonisotopic detection techniques that produce color $^{(30,51)}$ and can be associated with an ELISA format. ${ }^{(20,21,52)}$ However, the linear response range is rather narrow (about 2 logs) ${ }^{(20)}$ and the technology is less sensitive, with a limit of quantitation around 1000 copies.

\section{THE QUANTITATIVE CREDIBILITY OF A PCR PROCEDURE IS INTIMATELY LINKED TO A THOROUGH UNDERSTANDING OF ITS LIMITS}

In this review, I have attempted to show that many combinational quantitative PCR methods exist. This diversity in published procedures, which demonstrates the vitality of the quantitative PCR field, is also its Achilles heel. In a given PCR experiment, if one only changes, for example, the current RNA target to its spliced counterpart or if one wants to move from ${ }^{32} \mathrm{P}$ to ${ }^{33} \mathrm{P}$ for safety reasons, chances are that the limits of the assay will have to be reevaluated. The extreme sensitivity of quantitative PCR to any changes in the conditions of the assay demands additional effort from the investigator to insure that the analysis is done inside the established limits of the method. Therein resides the challenge. Because there are no rules on how to "rein in" a quantitative PCR assay, it may be made loose or tight depending on the controls.

\section{Detailed Description of the "Quantitative Frame"}

First, the very precise experimental conditions or "quantitative frame" in which the limits of quantitation were established must be described in detail. I shall illustrate this point through a series of examples.

It is commonplace to encounter a full evaluation of the reproducibility of a quantitative method without knowing at the end if the authors were assessing the method's intra- or interassay limits. On another level, many investigators, including ourselves, have mentioned the use of external DNA standards for the quantitation of minute amounts of specific DNA targets like HIV-1. ${ }^{(15)}$ Interassay limits of these procedures have been established, but what we have all failed to highlight is that the established limits are reliable only as long as one is using the same batch of standards within a given study. Indeed, we have found that even by preparing equivalent standards from the same HIV-1 DNA source, one might get enough variability between standards such that the established interassay limits are only valid if one is using the same batch of control DNA. This is not trivial at all and it has some serious implications. For example, if one wants to monitor a possible relapse in a leukemic patient over a couple of years and be in a position to draw any conclusions based on quantitative PCR, it follows that if the samples have to be run at different times, the same standard must be used. It also follows that a better approach would be to run all samples in the same PCR.

Finally, a detailed description of how to obtain consistency in the addition of synthetic RNA standards in quantitative RNA methods should be given. On one hand, it is inconvenient to prepare the RNA standard from scratch each time. On the other hand, because the amount of RNA standard added to the reaction is infinitesimal, it has to be controlled to account for possible degradation or loss. A convenient way to insure this consistency is to dilute the synthetic RNA control in a carrier RNA, such as yeast tRNA, 
down to the level of, for example, 1000 copies per $1 \mu \mathrm{g}$ and then to precipitate in ethanol and freeze at $-70^{\circ} \mathrm{C}$, where it can be kept for years. ${ }^{(22)}$ When needed, the precipitated RNA is centrifuged and the total amount is quantitated by an O.D. reading at 260 . This would immediately ensure the addition of 1000 copies of standard RNA for every recovered microgram of yeast tRNA. Detailed procedures such as this would help in enhancing confidence in data obtained from quantitative PCR analyses.

\section{Assessment of the Assay Limits}

The second parameter that one should consider is the assessment of the limits of quantitative assays. This is the ultimate key to quantitative PCR. Without a good working knowledge of the assay limits there can be no quantitation.

Validation of quantitative PCR methods involves the evaluation of the following items: sensitivity, specificity, accuracy, precision, reproducibility, and linear range. ${ }^{(59,60)}$ It is important to redefine part of this terminology in the context of PCR because there is confusion throughout the literature. In most of the described methodologies, the issues of sensitivity and specificity have been addressed rather convincingly. It is important to mention that the relevant sensitivity limit in a quantitative setting is the limit of quantitation rather than the limit of detection, i.e., the ability to measure precisely and/or accurately the number of DNA copies versus the ability to detect the lower limit of the assay. The real issue is linked to precision, reproducibility, and to a lesser extent accuracy. Indeed, most investigators are interested in comparing relative amounts of nucleic acids molecules instead of determining their absolute number. Therefore, it is more important to determine assay variability instead of accuracy. Variability is comprised of precision and reproducibility. Precision represents the degree of agreement among individual test results obtained by repeatedly applying the method to multiple samplings of a homogeneous sample. Thus, for the assessment of the interassay limits, precision is the key factor that must be determined. Reproducibility is a measurement of variability between assays where conditions might change slightly, such as the use of a different batch of labeled primers or different tubes of en- zyme. Thus, the variability in assays run at different times will be gauged by the combination of reproducibility and precision. It follows that the least amount of variability should be obtained when samples are run in the same assay. By definition, the best way to assess precision is to run many samples a number of times in the same assay and the best way to gauge reproducibility is to run many samples in a number of different assays. Precision and reproducibility should be measured inside the linear range of the assay. Statistical analyses are then implemented to define, on samples encompassing the linear range, the degree of precision and reproducibility of the assay. These concepts can be illustrated with a number of examples.

The first two examples concern precision. In both settings, the goal of the quantitative PCR is to monitor the amount of HIV DNA in the blood of patients under therapy. These analyses require the highest level of precision possible. In our first example, the authors developed a PCR procedure in which HIV-1 and HLA sequences were coamplified and then detected using a liquid hybridization approach followed by gel electrophoresis and AMBIS quantitation. ${ }^{(23)}$ To define a change in HIV viral DNA content in PBMCs, Aoki et al. evaluated the precision of their assay by running 10 replicates of a given lysate in a representative test. They chose to use a change of $19.2 \%$, which represents two times the standard deviation, as a cutoff value to call an increase or decrease in viral load significant. This number represents extremely good precision. However, it is important to mention that this value is valid in a very restricted quantitative setting. For example, it does not take into account the fluctuation in the amount of starting material that will inevitably weaken the level of precision. Furthermore, because the $19.2 \%$ cutoff was obtained with only one lysate, it is difficult to judge if such precision is also valid for HIV copy numbers encompassing the full linear range of the assay. Last, the authors presented $95 \%$ confidence intervals. However, a more adequate assessment of the precision in this type of assay would be to use $95 \%$ tolerance intervals that are population percentile intervals. Indeed, the calculation of these intervals would be appropriate for the quantitative analysis of HIV DNA molecules in the multiple bleeds ob- tained during the trial for a given patient.

Our own work on HIV provides the second example. The HIV DNA quantitative assay that we have developed has a linear range of 2 orders of magnitude from 10 to 1000 copies. We used a PCR format in which HIV copy numbers are normalized to the genomic DNA load through the quantitation of a globin amplicon coamplified with its HIV counterpart. ${ }^{(53)}$ Our goal was to monitor patients undergoing immunotherapy, meaning that we were interested in assessing relative changes in copy numbers with the best exactness possible. We had the luxury of running all the bleed samples of a given patient in the same PCR assay at the end because the trial was blinded. Therefore, assessment of the precision of the assay was our goal. To evaluate it, we analyzed 15 different bleeds encompassing 10 to 1000 copies and, because each sample for the trial is run in duplicates, we ran four duplicates of each of the 15 bleeds. To estimate the measurement variability, an analysis of variance was performed using the logarithm of the number of DNA copies. The unexplained variability ${ }^{(61)}$ was used to estimate the measurement error for one sample from one subject. A $95 \%$ tolerance interval was constructed using this estimate of measurement error. ${ }^{(62)}$ The limits of the tolerance interval translate into percent change. Thus, an increase of $60 \%$ or more in the number of HIV DNA copies or a decrease of $38 \%$ or more is significantly greater than what could be explained by random or experimental error and can be attributed to a change in the HIV-1 status of a subject. We believe that this type of validation allows a fairly accurate evaluation of the limit of the assay. In addition, the "quantitative PCR frame," in which the estimated limits are valid, is very clear. Thus, it allows the experimenter to check on the reality of those very limits quite easily. Such verifications should become routine in clinical settings. As shown in Figure 1, we challenged our assay limits by running the same bleed from 3 patients five times in the same PCR assay. We have demonstrated that for each patient, all quintuplet PCR values fall inside the previously established limits, i.e., less than $60 \%$ increase or $38 \%$ decrease in the copy number value does not represent a significant change (Table 1 ).

Other groups have reported that 

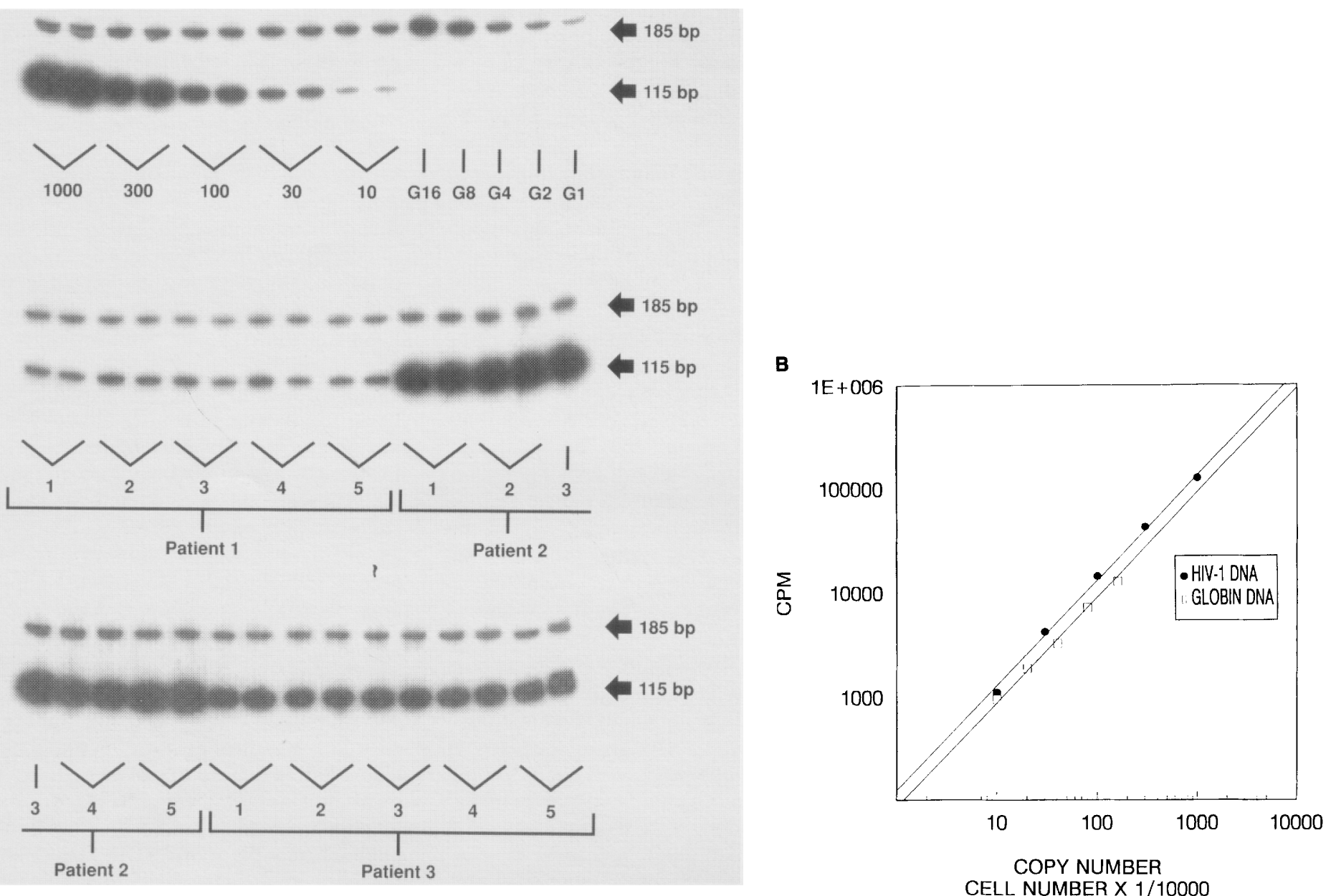

FIGURE 1 (A, higher panel) From 1000 to 10: autoradiogram of serial dilutions of 85-14-F2 cells (containing one truncated HIV-1 genome per cell) From G16 to G1: autoradiogram of serial dilutions of HIV-1 seronegative PBMCs. Coamplifications were performed on duplicate samples using ${ }^{32} \mathbf{P}$ end-labeled HIV-1 primers ( 30 cycles) and globin primers ( 15 cycles) in which 1000 to 10 represent the starting amount of HIV-1 copies diluted in $4 \times 10^{5}$ seronegative PBMCs and G16 to G1 represent $16 \times 10^{5}$ to $10^{5}$ PBMCs respectively. The 115-bp and 185-bp bands represent the HIV-1 and globin amplicons, respectively. $(A$, lower panel) Autoradiogram of quintuplet runs on duplicate samples of the same bleed for 3 patients. The coamplifications were performed in the same PCR assay as the above controls. $(B)$ Counts per minute from the HIV-1 and globin bands were quantitated using the AMBIS Radioanalytic Imaging System and used to generate standard curves, i.e., plot of natural log of cpm versus natural log of copy number or cell number.

rather precise quantitation of specific DNA molecules is achievable. ${ }^{(16,19,52,54-56)}$ It is also well recognized that the level of precision attainable by PCR RNA is much lower, due in part to the addition of a second enzymatic step, the reverse transcription, and in part to the fact that most of the current RNA controls carry a certain level of variability intrinsically. However, we have shown that under very controlled conditions, a change as low as $100 \%$ can represent a significant increase in RNA copies. ${ }^{(22)}$

If it is clear that great precision is attainable by PCR, this is not the case for reproducibility. The level of reproducibility described in the literature spans a rather large range from 2- to- 10 fold. ${ }^{(15,19,20,44,57)}$ As is the case for precision, better reproducibility is obtained with PCR DNA assays than with RNA assays. In addition, as previously mentioned, great care has to be used when the goal is to compare samples run in different assays quantitatively. Indeed, if too many elements are changed between assays, for example, shifting from one batch of standards or primers, it might greatly weaken the reproducibility of the assay to a point where comparative analyses become pointless.

Of course, commitments to a thorough validation of quantitative PCR assays might be overkill for a number of applications. I would argue, however, that regardless of the level of reproduc- ibility and precision required in a given study, these items should be addressed systematically. This would ultimately eliminate the notion of "semi-quantitative," which in my mind is simply meaningless and even dangerous. Indeed, it is not rare to encounter in the same paper the word "semi-quantitative" associated with quantitative conclusions.

\section{FINAL NOTE}

In the last two decades, biologists have been using a panoply of molecular tools, such as Southern or Northern blotting, to quantitate nucleic acids. With these tools, extra care was also needed to generate quantitative information. How- 
TABLE 1 Calculation of HIV-1 Copy Numbers

\begin{tabular}{cccc}
\hline $\begin{array}{l}\text { Patient } \\
\text { number }\end{array}$ & $\begin{array}{l}\text { Lower } \\
\text { boundary }\end{array}$ & $\begin{array}{l}\text { HIV-1 } \\
\text { copy } \\
\text { number }\end{array}$ & $\begin{array}{l}\text { Upper } \\
\text { boundary }\end{array}$ \\
\hline 1 & 21 & 34 & 55 \\
1 & 28 & 45 & 72 \\
1 & 27 & 43 & 69 \\
1 & 22 & 36 & 58 \\
1 & 21 & 33 & 53 \\
2 & 344 & 551 & 883 \\
2 & 504 & 807 & 1294 \\
2 & 515 & 825 & 1322 \\
2 & 321 & 515 & 826 \\
2 & 475 & 761 & 1220 \\
3 & 99 & 158 & 253 \\
3 & 85 & 136 & 218 \\
3 & 118 & 189 & 303 \\
3 & 92 & 148 & 237 \\
3 & 82 & 132 & 212 \\
\hline
\end{tabular}

From the cpm, HIV-1 copy numbers were calculated using the regression coefficients obtained from the standard curve and were normalized to the genomic DNA load through the amplification of globin. The lower and upper boundaries were obtained by multiplying the HIV-1 copy number by 0.624 (38\% decrease) and 1.603 (60\% increase), respectively.

ever, unlike PCR, a more universal quantitative frame was rapidly put together and common sense controls, like running standards to create standard curves or straightforward internal controls, generally served to provide a level of confidence in the quantitative data. In PCR settings, there is a certain awareness that, because of the amplification process, common sense controls are no longer sufficient to generate enough confidence in the quantitative power of the assay (which is true). The problem arises when these controls are the only ones called upon to build the entire quantitative frame, a situation that unfortunately is still often the case. The amazing thing about quantitative PCR methodologies reported throughout the literature is that most of the time the reader senses a strong effort directed at optimizing the assays, and, most of the time, issues like the sensitivity and the specificity of the assay are adequately covered. However, too often, one cannot sense an equivalent dedication for the assessment of the limits of the assay in terms of precision, reproducibility, and accuracy, which should be the easier part. One can do the best optimization in the world, achieve the best sensitivity and specificity, and yet the real quantitative ability of an assay would be at best only elusive without a strong validation analysis to back it up. I have attempted to demonstrate what is necessary to achieve quantitation by PCR. It is a "simple" two-step procedure: first optimization and second validation. If done properly, PCR becomes a very powerful quantitative tool.

\section{ACKNOWLEDGMENTS}

I thank Stacey Griffin, Annie Marchese, and Patrick Pezzoli for expert technical assistance. I am grateful to Drs. Dennis Carlo, Anne Daigle, Fred Jensen, Steve Richieri, and Richard Trauger for hepful comments and critical evaluation of the manuscript. I would also like to thank Dr. Denis Henrard for his personal communication. This work was supported by The Immune Response Corporation.

\section{REFERENCES}

1. Erlich, H.A., R. Gibbs, and H.H. Kazazian, Jr., eds. 1989. Polymerase chain reaction. Current communications in molecular biology. Cold Spring Harbor Laboratory, Cold Spring Harbor, New York.

2. Erlich, H.A., ed. 1989. PCR technology: Principles and applications for DNA amplification. Stockton Press

3. Mullis, K.B. and F. Faloona. 1987. Specific synthesis of DNA in vitro via a polymerase catalysed chain reaction. Methods Enzymol. 155: 335-350.

4. Mullis, K.B., F.A. Faloona, S. Scharf, G.T. Horn, and H.A. Erlich. 1986. Specific enzymatic amplification of DNA in vitro: The polymerase chain reaction. Cold Spring Harbor Symp. Quant. Biol. 51: 263.

5. Mullis, K.B. 1991. The polymerase chain reaction in an anemic mode: How to avoid cold oligodeoxyribonuclear fusion. PCR Methods and Applications 1: 1-4.

6. Noonan, K.E., C. Beck, T.A. Holzmayer, J.E. Chin, J.S. Wunder, I.L. Andrulis, A.F. Gazdar, C.L. Willman, B. Griffith, D.D. Von Hoff, and I.B. Roninson. 1990. Quantitative analysis of MDR1 (multidrug resistance) gene expression in human tumors by polymerase chain reaction. Proc. Natl. Acad. Sci. 87: 7160-7164.

7. Murphy, L.D., C.E. Herzog, J.B. Rudick, A.T. Fojo, and S.E. Bates. 1990. Use of the polymerase chain reaction in the quantitation of mdr-1 gene expression. Biochemistry 29: 10351-10356.

8. Park, O-K. and K.E. Mayo. 1991. Transient expression of progesterone receptor messenger RNA in ovarian granulosa cells af- ter the preovulatory luteinizing hormone surge. Mol. Endocrinol. 5: 967-978.

9. Wang, M., M.V. Doyle, and D.F. Mark. 1989. Quantitation of mRNA by the polymerase chain reaction. Proc. Natl. Acad. Sci. 86: 9717-9721.

10. Innis, M.A., D.H. Gelfand, J.J. Sninsky, and T.J. White eds. 1990. PCR protocols: $a$ guide to methods and applications. Academic Press, New York.

11. Erlich, H.A., D. Gelfand, and J.J. Sninsky. 1991. Recent advances in the polymerase chain reaction. Science 252: 1643-1651.

12. Saiki, R.K., D.H. Gelfand, S. Stoffel, S.J. Scharf, R. Higuchi, G.T. Horn, K.B. Mullis, and H.A. Erlich. 1988. Primer-directed enzymatic amplification of DNA with a thermostable DNA polymerase. Science 239: 487-491.

13. Bej, A.K., M.H. Mahbubani, and R.M. Atlas. 1991. Amplification of nucleic acids by polymerase chain reaction (PCR) and other methods and their applications. Crit. Rev. Biochem. Mol. Biol. 26: 301-334.

14. Faloona, F., S. Weiss, F. Ferre, and K.B. Mullis, personal communication.

15. Ferre, F., A. Marchese, P.C. Duffy, D.E. Lewis, M.R. Wallace, H.J. Beecham, K.G. Burnett, F.C. Jensen, and D.J. Carlo. 1992. Quantitation of HIV viral Burden by PCR in HIV seropositive Navy personnel representing Walter Reed staging 1 to 6. AIDS Res. Hum. Retrovir. 8: 269-275.

16. Lee, T., F.J. Sunzeri, L.H. Tobler, B.G. Williams, and M.P. Busch. 1990. Quantitative assessment of HIV-1 DNA load by coamplification of HIV-1 gag and HLADQ- $\alpha$ genes. AIDS 5: 683-691.

17. Nielson, K. and E.J. Mathur. 1990. Perfect match enhancer: Limits false priming events during amplification reactions. Strategies Mol. Biol. 3: 17.

18. Kellogg, D.E., J.J. Sninsky, and S. Kwok. 1990. Quantitation of HIV-1 proviral DNA relative to cellular DNA by the polymerase chain reaction. Anal. Biochem. 189: 202-208.

19. Oka, S., K. Urayama, Y. Hirabayashi, K. Ohnishi, H. Goto, K. Mitamura, S. Kimura, and K. Shimada. 1990. Quantitative analysis of human immunodeficiency virus type- 1 DNA in asymptomatic carriers using the polymerase chain reaction. B.B.R.C. 167: 1-8.

20. Holodniy, M., D.A. Katzenstein, S. Sengupta, A.M. Wang, C. Casipit, D.H. Schwartz, M. Konrad, E. Groves, and T.C. Merigan. 1991a. Detection and quantification of human immunodeficiency virus RNA in patient serum by use of the polymerase chain reaction. I. Infect. Dis. 163: 862-866.

21. Holodniy, M., D.A. Katzenstein, D.M. Israelski, and T.C. Merigan. 1991b. Reduction in plasma human immunodeficiency virus ribonucleic acid after dideoxynucleoside therapy as determined 
by the polymerase chain reaction. J. Clin. Invest. 88: 1755-1759.

22. Ferre, F., P. Pezzoli, P.C. Duffy, F.C. Jensen, and D.J. Carlo, in preparation.

23. Aoki, S., R. Yarchoan, R.V. Thomas, J.M. Pluda, K. Marczyk, S. Broder, and H. Mitsuya. 1990. Quantitative analysis of HIV-1 proviral DNA in peripheral blood mononuclear cells from patients with AIDS and ARC: Decrease of proviral DNA content following treatment 2', 3'-dideoxyinosine (ddI). AIDS Res. Hum. Retrovir. 6: 13311339.

24. Pang, S., Y. Koyanagi, S. Miles, C. Wiley, H.V. Vinters, and I.S.Y. Chen. 1990. High levels of unintegrated HIV-1 DNA in brain tissue of AIDS dementia patients. Nature 343: $85-89$.

25. Genesca, J., R.Y. Wang, H.J. Alter, and J.W. Shih. 1990. Clinical correlation and genetic polymorphism of the human immunodeficiency virus proviral DNA obtained after polymerase chain reaction amplification. J. Infect. Dis. 162: 10251030.

26. Schnittman, S., .C. Psallidopoulos, H.C. Lane, L. Thompson, M. Baseler, F. Massari, C.H. Fox, N.P. Salzman, and A.S. Fauci. 1989. The reservoir for HIV-1 in human peripheral blood is a $\mathrm{T}$ cell that maintains expression of CD4. Science 245: 305-308.

27. Ou, C-Y., S.H. McDonough, D. Cabanas, T.B. Ryder, M. Harper, J. Moore, and G. Schochetman. 1990. Rapid and quantitative detection of enzymatically amplified HIV-1 DNA using chemiluminescent oligonucleotide probes. AIDS Res. Hum. Retrovir. 6: 1323-1329.

28. Landgraf, A., B. Reckmann, and A. Pingoud. 1991. Quantitative analysis of polymerase chain reaction (PCR) products using primers labeled with biotin and a fluorescent dye. Anal. Biochem. 193: 231235.

29. Simmonds, P., P. Balfe, J.F. Peutherer, C.A. Ludlam, J.O. Bishop, and A.J. Leigh Brown. 1990. Human immunodeficiency virus infected individuals contain provirus in small numbers of peripheral mononuclear cells and at low copy numbers. $J$. Virol. 64: 864-872.

30. Lundeberg, J., J. Wahlberg, and M. Uhlen. 1991. Rapid colorimetric quantification of PCR-amplified DNA. BioTechniques 10: $68-75$.

31. Gilliland, G., S. Perrin, and H.F. Bunn. 1990. Competitive PCR for quantitation of mRNA. In PCR Protocols (ed. M.A. Innis, D.H. Gelfand, J.J. Sninsky, and T.J. White), pp. 60-69. Academic Press, New York.

32. Uberla, K., C. Platzer, T. Diamanstein, and T. Blankenstein. 1991. Generation of competitor DNA fragments for quantitative PCR. PCR Methods Applic. 1: 136-139.

33. Zack, J.A., S.J. Arrigo, S.R. Weitsman, A.L.
Go, A. Haislip, and I.S.Y. Chen. 1990. HIV-1 entry into quiescent primary lymphocytes: molecular analysis reveals a labile, latent viral structure. Cell 61:213222.

34. Henrard, D.R., W.F. Mehaffey, and J.P. Allain. 1992. A sensitive viral capture assay for detection of plasma viremia in HIV infected individuals. AIDS Res. Hum. Retrovir. 68: 47-52.

35. Li, B., P.K. Sehajpal, A. Khanna, H. Vlassara, A. Cerami, K.H. Stenzel, and M. Suthanthiran. 1991. Differential regulation of transforming growth factor $\beta$ and interleukin 2 genes in human T cells: Demonstration by usage of novel competitor DNA constructs in the quantitative polymerase chain reaction. J. Exp. Med. 174: 1259-1262.

36. Simmonds, P., L.Q. Zhang, H.G. Watson, S. Rebus, E.D. Ferguson, P. Balfe, G.H. Leadbetter, P.L. Yap, J.F. Peutherer, and C.A. Ludlam. 1990. Hepatitis C quantification and sequencing in blood products, haemophiliacs, and drug users. Lancet 336: 1469-1472.

37. Hoof, T., J.R. Riordan, and B. Tummler. 1991. Quantitation of mRNA by the kinetic polymerase chain reaction assay: $\mathrm{A}$ tool for monitoring P-glycoprotein gene expression. Anal. Biochem. 196: 161-169.

38. Michael, N.L., M. Vahey, D.S. Burke, and R.R. Redfield. 1992. Viral DNA and mRNA expression correlate with the stage of human immunodeficiency virus (HIV) type 1 infection in humans: evidence for viral replication in all stages of HIV disease. $J$. Virol. 66: 310-316.

39. Henrard, D.R., personal communication. 40. Abe, J., B.L. Kotzin, K. Jujo, M.E. Melish, M.P. Glode, T. Kohsaka, and D.Y.M. Leung. 1992. Selective expansion of T cells expressing T-cell receptor variable regions $\mathrm{V} \beta 2$ and $\mathrm{V} \beta 8$ in Kawasaki disease. Proc. Natl. Acad. Sci. 89: 4066-4070.

41. Chelly, J., J.C. Kaplan, P. Maire, S. Gautron, and A. Kahn. 1988. Transcription of the dystrophin gene in human muscle and nonmuscle tissues. Nature 333: 858-860.

42. Chelly, J., G. Hamard, A. Koulakoff, J-C. Kaplan, A. Kahn, and Y. Berwald-Netter. 1990. Dystrophin gene transcribed from different promoters in neuronal and glial cells. Nature 344: 64-65.

43. Chelly, J., D. Montarras, C. Pinset, Y. Berwald-Netter, J.C. Kaplan and A. Kahn. 1990. Quantitative estimation of minor mRNAs by cDNA-polymerase chain reaction: Application to dystrophin mRNA in cultured myogenic and brain cells. Eur. J. Biochem. 187: 691-698.

44. Feldman, A.M., P.E. Ray, C.M. Silan, J.A. Mercer, W. Minobe, and M.R. Bristow. 1991. Selective gene expression in failing human heart: Quantification of steadystate levels of messenger RNA in endom- yocardial biopsies using the polymerase chain reaction. Circulation 83: 18661872.

45. Sperison, P., S.M. Wang, P. Reichenbach, and M. Nabholz. 1992. A PCR-based assay for reporter gene expression. PCR Methods Applic. 1: 164-170.

46. Becker-Andre, M. and K. Hahlbrock. 1989. Absolute mRNA quantification using the polymerase chain reaction (PCR). A novel approach by a PCR aided transcript titration assay (PATTY). Nucleic Acids Res. 17: 9437-9446.

47. Lin, J.H-C., B. Grandchamp, and N.G. Abraham. 1991. Quantitation of human erythroid-specific porphobilinogen deaminase mRNA by the polymerase chain reaction. Exp. Hematol. 19: 817-822.

48. Stieger, M., C. Demolliere, L. AhlbornLaake, and J. Mous. 1991. Competitive polymerase chain reaction assay for quantitation of HIV-1 DNA and RNA. $J$. Virol. Methods 34: 149-160.

49. Singer-Sam, J., J.M. LeBon, A. Dai, and A.D. Riggs. 1992. A sensitive, quantitative assay for measurement of allele-specific transcripts differing by a single nucleotide. PCR Methods Applic. 1: 160-163.

50. Arnold, L.J., P.W. Hammond, W.A. Wiese, and N.C. Nelson. 1989. Assay formats involving acridinium-ester-labeled DNA probes. Clin. Chem. 35: 1588-1594.

51. Syvanen, A-C., M. Bengtstrom, J. Tenhunen, and H. Soderlund. 1988. Quantification of polymerase chain reaction products by affinity-based hybrid collection. Nucleic Acids Res. 16: 11327-11338.

52. Eron, J.J., P. Gorczyca, J.C. Kaplan, and R.T. D'Aquila. 1992. Susceptibility testing by polymerase chain reaction DNA quantitation: A method to measure drug resistance of human immunodeficiency virus type 1 isolates. Proc. Natl. Acad. Sci. 89: 3241-3245.

53. Ferre, F., A. Marchese, S.L. Griffin, F.C. Jensen, and D.J. Carlo, in preparation.

54. Dickover, R.E., R.M. Donovan, E. Goldstein, S. Dandekar, C.E. Bush and J.R. Carlson. 1990. Quantitation of human immunodeficiency virus DNA by using the polymerase chain reaction. J. Clin. Microb. 28: 2130-2133.

55. Warren, W., T. Wheat, and P. Knudsen. 1991. Rapid analysis and quantitation of PCR products by high-performance liquid chromatography. BioTechniques 11: 250255.

56. Golay, J., F. Passerini, and M. Introna. 1991. A simple and rapid method to analyze specific mRNAs from few cells in a semi-quantitative way using the polymerase chain reaction. PCR Methods Applic. 1: 144-145.

57. Davis, G.R., K. Blumeyer, L.J. DiMichele, K.M. Whitfield, H. Chappelle, N. Riggs, S.S. Ghosh, P.M. Kao, E. Fahy, D.Y. Kwoh, J.C. Guatelli, S.A. Spector, D.D. Richman, 
and T.R. Gingeras. 1989. Detection of HIV-1 in AIDS patients using amplification-mediated hybridization analyses: reproducibility and quantitative limitations. J. Infec. Dis. 162: 13-20.

58. Rappolee, D.A., D. Mark, M.J. Banda, and Z. Werb. 1988. Wound macrophages express TGF- $\alpha$ and other growth factors in vivo: Analysis by mRNA phenotyping. $\mathrm{Sci}$ ence 241: 708-712.

59. United States Pharmacopeia. 1990. XXII, Part 1125: 1710-1712.

60. Paul, W.L. 1991. USP perspectives on analytical methods validation: Pharmaceutical Technology, March, pp. 130-141.

61. Hicks, C.R. 1973. Fundamental concepts in the design of experiments, 2 nd ed., see Section 10.3: 175-177. Holt, Rinehart, Winston, New York.

62. Odeh, R.E. and D.B. Owen: 1980. Tables for normal tolerance limits, sampling plans, and screening, vol. 32. Marcel Dekker, New York.

63. Porcher C., M-C. Malinge, C. Picat, and B. Grandchamp. 1992. A simplified method for determination of specific DNA or RNA copy number using quantitative PCR and an automatic DNA sequencer. BioTechniques 13: 106-113. 


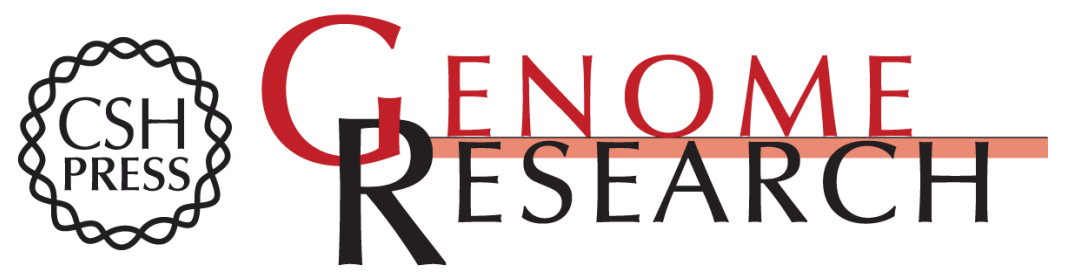

\section{Quantitative or semi-quantitative PCR: reality versus myth.}

F Ferre

Genome Res. 1992 2: 1-9

Access the most recent version at doi:10.1101/gr.2.1.1

References This article cites 51 articles, 15 of which can be accessed free at:

http://genome.cshlp.org/content/2/1/1.full.html\#ref-list-1

\section{License}

Email Alerting Receive free email alerts when new articles cite this article - sign up in the box at the Service top right corner of the article or click here.

\section{Affordable, Accurate Sequencing.}

To subscribe to Genome Research go to: https://genome.cshlp.org/subscriptions 